\title{
Retraction
}

\section{Retracted: A Rare Reason for Pelvic Pain in Pregnancy: Infectious Sacroiliitis}

\author{
Case Reports in Medicine
}

Received 25 November 2020; Accepted 25 November 2020; Published 22 December 2020

Copyright $\odot 2020$ Case Reports in Medicine. This is an open access article distributed under the Creative Commons Attribution License, which permits unrestricted use, distribution, and reproduction in any medium, provided the original work is properly cited.

Case Reports in Medicine has retracted the article titled "A Rare Reason for Pelvic Pain in Pregnancy: Infectious Sacroiliitis" [1] as it was found to contain text in the Introduction and Discussion sections that was taken from previously published articles, without citation $[2,3]$. The sources are as follows:

(i) M. L. Moros, C. Rodrigo, A. Villacampa et al., "Septic shock in pregnancy due to pyogenic sacroiliitis: a case report," Journal of Medical Case Reports, vol. 3, p. 6505, 2009, https://doi.org/10.1186/1752-1947-36505.

(ii) D. Mahovic, N. Laktasic-Zerjavic, K. Tudor et al., "Pregnancy-related severe pelvic girdle pain caused by unilateral noninfectious sacroiliitis," Zeitschrift für Rheumatologie, vol. 73, pp. 665-668, 2014, https://doi.org/10.1007/s00393-013-1323-6.

The authors did not approve the retraction, which was recommended by the editorial board.

\section{References}

[1] Y. Cekmez, A. Göçmen, O. Arslan, F. Şanlıkan, and S. Bağc1 Türkmen, "A rare reason for pelvic pain in pregnancy: infectious sacroiliitis," Case Reports in Medicine, vol. 2015, pp. 1-3, Article ID 690429, 2015.

[2] M. L. Moros, C. Rodrigo, A. Villacampa, J. Ruiz, and C. Lapresta, "Septic shock in pregnancy due to pyogenic sacroiliitis: a case report," Journal of Medical Case Reports, vol. 3, no. 1, p. 6505, 2009.

[3] D. Mahovic, N. Laktasic-Zerjavic, K. I. Tudor, I. Mercep, M. Prutki, and B. Anic, "Pregnancy-related severe pelvic girdle pain caused by unilateral noninfectious sacroiliitis," Zeitschrift für Rheumatologie, vol. 73, no. 7, pp. 665-668, 2014. 